\title{
Promoted Zinc Chromite Catalysts for Higher Alcohol Synthesis Semi-Annual Report
}

Reporting Period Start Date: October 01, 1999

Reporting Period End Date: $\quad$ March 31, 2000

$\begin{array}{ll}\text { Principal Authors: } & \text { Ms. Xiaolei Sun } \\ & \text { Professor George W. Roberts }\end{array}$

Date Report Issued: $\quad$ August 29, 2000

DOE Award Number: DE-FG26-97FT97262--05

North Carolina State University

Department of Chemical Engineering

Box 7905

Raleigh, NC 27695-7905 


\section{Disclaimer:}

This report was prepared as an account of work sponsored by an agency of the United States Government. Neither the United States Government nor any agency thereof, nor any of their employees, makes any warranty, express or implied, or assumes any legal liability or responsibility for the accuracy, completeness, or usefulness of any information, apparatus, product, or process disclosed, or represents that its use would not infringe privately owned rights. Reference herein to any specific commercial product, process, or service by trade name, trademark, manufacturer, or otherwise does not necessarily constitute or imply its endorsement, recommendation, or favoring by the United States Government or any agency thereof. The views and opinions of authors expressed herein do not necessarily state or reflect those of the United States Government or any agency thereof.

\section{Patent Information:}

No patentable subject matter is disclosed in this report. 


\section{Abstract}

During this reporting period, a "zinc chromite" catalyst promoted with 6 wt.\% cesium (Cs) was evaluated at the following conditions: Temperature $375^{\circ} \mathrm{C}$; Total Pressure - 6.8 MPa (1000 psig); Gas Hourly Space Velocity (GHSV) - 5000 standard liters $/ \mathrm{kg}$ (cat)-hr, and; $\mathrm{H}_{2} / \mathrm{CO}$ feed ratio $-1.0 \mathrm{~mole} / \mathrm{mole}$. Decahydronaphthalene (DHN) was used as the slurry liquid. The experiment lasted for eight days of continuous operation.

Although the experimental data once again did not exhibit the desired degree of consistency, the data did show that methanol was the primary reaction product. The slurry liquid did not decompose or alkylate to a measurable extent during the continuous 8-day experiment. There was a relatively significant loss of catalyst surface area during the experiment.

Gas chromatography/mass spectrometry (GC/MS) analysis of various fractions of "spent" THQ was carried out. The fractions were prepared by silica gel liquid chromatography (LC). Chemical formuli and probable structures for each major compound were obtained. However, a higher degree of purification will be necessary to allow nuclear magnetic resonance (NMR) analysis to be used for definitive compound identification.

A new Maxpro gas booster (DLE 15-75) was purchased because the existing Haskel gas booster once again developed a severe leak of carbon monoxide and hydrogen, and was judged to be unworthy of repair. 


\section{Table of Contents}

$\underline{\text { Page }}$

Abstract

$\begin{array}{ll}\text { Executive Summary } & 1\end{array}$

A. Introduction 2

B. Results and Discussion 3

1. New Gas Booster Design 3

2. Evaluation of Promoted Zinc Chromite Catalyst 3

a. Catalyst Preparation 3

b. Catalyst Evaluation 4

c. Data Collection 4

i. On-Line GC Analysis System 4

ii. Liquid Sample Collection 5

iii. Catalyst Characterization 5

d. Results and Discussion 5

i. Gas Product Analysis 5

ii. Liquid Analysis 9

iii. Catalyst Characterization 9

e. Future Research 9

3. Analysis of Slurry Liquid 9

$\begin{array}{ll}\text { C. Conclusions } & 11\end{array}$

$\begin{array}{ll}\text { D. References } & 12\end{array}$ 
List of Tables:

Table 2.1: Total Oxygenates and Hydrocarbons Selectivities for

Table 2.2: Surface Area of Fresh and Spent Catalysts 9

Table 3.1: GC/MS Analysis Results 11

List of Figures:

Figure 2.1: Catalyst Productivities for Zinc Chromite Promoted with 6 wt.\% Cs and with 3 wt.\% Cs, and for Unpromoted Zinc Chromite Catalyst

Figure 2.2: Catalyst Selectivities for Zinc Chromite Promoted with 6 wt.\% Cs and with 3 wt.\% Cs, and for Unpromoted Zinc Chromite Catalyst 


\section{Executive Summary}

The overall objective of this research project is to evaluate promoted "zinc chromite" catalysts for the production of higher $\left(\mathrm{C}_{2}^{+}\right)$alcohols in a slurry reactor, using synthesis gas as the feedstock.

During this reporting period, a "zinc chromite" catalyst promoted with 6 wt.\% cesium (Cs) was evaluated using an existing Maxpro gas booster (DLE 30). Use of this compressor was necessary because the Haskel gas booster that had been used in previous experiments developed another serious leak of carbon monoxide and hydrogen. Due to a limitation of the Maxpro gas booster, the operating pressure for the catalyst evaluation had to be reduced to $6.8 \mathrm{MPa}$ (1000psig) from the normal level of $2000 \mathrm{psig}$. In an attempt to compensate for the lower pressure, the $\mathrm{H}_{2} / \mathrm{CO}$ feed ratio was increased from the normal value of 0.5 to $1.0 \mathrm{~mole} / \mathrm{mole}$. The other operating conditions were identical to previous experiments (1), i.e., Temperature $-375^{\circ} \mathrm{C}$ and Gas Hourly Space Velocity (GHSV) - 5000 standard liters/kg(cat)-hr. Decahydronaphthalene (DHN) was the slurry liquid. The experiment lasted for eight days of continuous operation. The gas product stream was analyzed using the new, on-line gas chromatographic (GC) system (2).

Even though there was considerable variability in the experimental data, a preliminary comparison of the performance of the $6 \mathrm{wt} \%$ Cs-promoted zinc chromite catalyst with that of a 3 wt.\% Cs-promoted catalyst (2) and with that of an unpromoted zinc chromite catalyst (3) was carried out. The primary product was methanol for all three catalysts. Gas chromatography/mass spectrometry (GC/MS) analyses showed that the slurry liquid did not decompose or alkylate during the 8-day run. Surface area measurements were performed for both fresh and used catalysts. The 6 wt.\% Cs catalyst showed a relatively large surface area loss during the testing period.

Two different gas/liquid (G/L) separator temperatures were tested to ensure that higher alcohols did not condense in the separator during the experiment. The $\mathrm{G} / \mathrm{L}$ separator temperature did not have a significant effect on the outlet gas composition.

Gas chromatography/mass spectrometry (GC/MS) analysis of various fractions of "spent" THQ was carried out. The fractions, about twenty in number, were prepared by silica gel liquid chromatography (LC). Chemical formuli and probable structures for each compound were obtained. However, a higher degree of purification will be necessary to allow Nuclear Magnetic Resonance (NMR) analysis to be used for definitive compound identification.

Based on the reliable operation of the existing Maxpro gas booster, a new Maxpro compressor of the same basic design, but capable of operating at 2000 psig., was purchased. The Haskell gas booster was not repaired because this compressor was considered unsuitable for the desired service. 


\section{A. Introduction}

Branched higher alcohols, such as isobutanol (2-methyl-1-propanol) or isoamyl alcohol (2-methyl-1-butanol) could provide the raw materials needed to produce novel cetane enhancers for diesel fuel, e.g., methyl isobutyl ether (MIBE). Branched alcohols also could be of interest per se as oxygenated additives for motor gasoline.

With the exception of fuel-grade ethanol, current processes for producing higher alcohols are based primarily on imported petroleum. The objective of this research is to explore the synthesis of higher alcohols, using synthesis gas as the starting raw material. Synthesis gas is a mixture containing primarily hydrogen $\left(\mathrm{H}_{2}\right)$ and carbon monoxide $(\mathrm{CO})$, which can be produced from a variety of domestically-available materials, e.g. coal, natural gas, and waste biomass.

Most previous attempts to produce branched higher alcohols from synthesis gas have been based on modified methanol synthesis catalysts, either the "low-pressure", $\mathrm{Cu} / \mathrm{ZnO}$ catalyst, or the "high-pressure", ZnCrO ("zinc chromite") catalyst. Either of these catalysts can be promoted with Group I elements such as potassium (K) and cesium (Cs) to shift the product distribution away from methanol towards higher alcohols.

Promoted "zinc chromite" catalysts are the focus of this research. All previous studies of this family of catalysts have been carried out in fixed-bed reactors. However, due to the highly exothermic character of higher alcohol synthesis (HAS), it is difficult to control the temperature of a fixed-bed reactor, especially on a pilot-plant or commercial scale. A slurry reactor, by contrast, has excellent heat removal capability and many other advantages that make this type of reactor ideal for HAS.

The synthesis of methanol in a slurry reactor, using an unpromoted "zinc chromite" catalyst, was studied in depth by two previous Ph.D students $(3,4)$. Three slurry liquids were identified that appeared to have the necessary thermal and chemical stability at $375^{\circ} \mathrm{C}$, in the presence of the unpromoted "zinc chromite" catalyst (5). These liquids were: decahydronaphthalene (Decalin $\AA$, $\mathrm{DHN}$ ), tetrahydronaphthalene (tetralin, THN), and tetrahydroquinoline (THQ). The rate of methanol synthesis was substantially higher in THQ that in the other two liquids. However, THQ was alkylated extensively during the reaction, raising questions about whether it participated in the catalytic cycle, and whether its composition would eventually stabilize. Details can be found in References 3 and 6. The present research involves the chemical analysis of the "spent" slurry liquid, i.e., the liquid in the reactor at the conclusion of experimentation, in order to understand the role of the slurry liquid in the catalytic process.

Some preliminary experiments were carried out with a 3 wt.\% Cspromoted "zinc chromite" catalyst by a previous M. Eng. student, and later by Ms. Xiaolei Sun under this contract (1). These prior experiments were qualitative in nature. However, they showed that the product contained significant concentrations of $\mathrm{C}_{2}^{+}$alcohols, $\mathrm{C}_{2}^{+}$olefins and $\mathrm{C}_{2}^{+}$paraffins. An on-line, gas chromatograph (GC) system was developed that appears to be capable of identifying and quantifying the broad spectrum of products obtained with 
promoted zinc chromite catalysts. Details of this system are contained in previous Semi-Annual Reports $(2,7,8)$.

Based on the prior work (1), the main objectives for this reporting period were:

1. To solve the problem of carbon monoxide/hydrogen leakage from the gas feed system by testing a different design of gas booster compressor;

2. To evaluate a "zinc chromite" catalyst promoted with 6 wt.\% Cs using a slurry reactor;

3. To continue the analysis of "spent" slurry liquid obtained from previous experiments with $\mathrm{THQ}$.

\section{B. Results and Discussion}

\section{New Gas Booster Design}

The Haskel gas booster that had been used for all previous experiments under this contract developed another major leak of the feed gas, a mixture of carbon monoxide and hydrogen, after about one-half year of relatively light use following a major rebuild. After inspection, the leak was attributed to deterioration of the booster's o-rings. A technician from the Haskel Company stated that this gas booster was not designed for continuous operation. Therefore, rapid deterioration of the o-rings was to be expected. Haskel had not taken this position in a number of prior conversations, over the past five to ten years.

An existing Maxpro gas booster (DLE-30) was then tested in the experiment described below and was found to give satisfactory performance. No leakage was experienced during eight days of continuous operation. After checking with the manufacturer concerning continuous operation, a new Maxpro gas booster (DLE 15-75) was purchased. This new compressor can be operated at the required pressures and flow rates. It cost approximately $\$ 5000$.

\section{Evaluation of Promoted Zinc Chromite Catalyst}

A zinc chromite catalyst promoted with 6 wt.\% Cs was evaluated. The experiment was performed at $6.8 \mathrm{MPa}(1000 \mathrm{psig})$ total pressure, since the existing Maxpro gas booster (DLE 30) was unable to operate in a stable manner at a higher discharge pressure. A preliminary comparison of the performance of this 6 wt.\% Cs-promoted catalyst with that of a 3 wt.\% Cs-promoted catalyst (1) and with that of an unpromoted zinc chromite catalyst $(3,6)$ was carried out.

\section{a. Catalyst Preparation}

The 6 wt.\% Cs-promoted zinc chromite catalyst (821A-2-37-2) was prepared by Engelhard Corporation using the incipient wetness technique. 
Reduced and stabilized Engelhard Zn-0312 catalyst was impregnated with a solution of $\mathrm{CsOH}$, and then dried at $125^{\circ} \mathrm{C}$ under $\mathrm{N}_{2}$. The catalyst was not calcined after the drying process. This lack of calcination may be significant, as discussed below.

\section{b. Catalyst Evaluation}

The catalyst was evaluated at one basic set of operating conditions for 8 days of continuous operation. The operating conditions were:

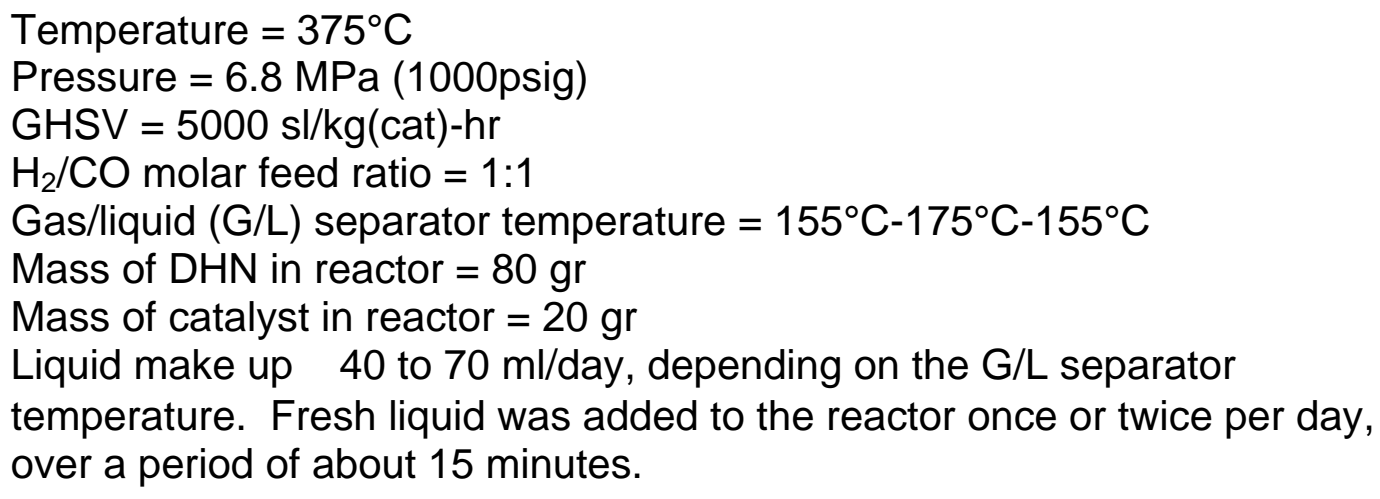

Originally, it was planned to use the same operating conditions as in previous experiments with 3 wt.\% Cs-promoted catalyst. However, as mentioned above, the present experiment had to be carried out at $6.8 \mathrm{MPa}(1000 \mathrm{psig})$ due to a limitation of the existing Maxpro gas booster. In the previous experiments, the total pressure was 2000 psig. Since a low operating pressure is not favorable for HAS, the $\mathrm{H}_{2} / \mathrm{CO}$ molar feed ratio was increased to 1.0 from the previous value of 0.5 . The higher ratio is supposed to give a better higher alcohols productivity $(9,10)$.

The purity of the feed gases, $\mathrm{CO}$ and $\mathrm{H}_{2}$, and the properties of the slurry liquid, DHN, are contained in last Semi-Annual Report (1).

Even though the catalyst is provided by Engelhard Corporation in a reduced and stabilized form, a reduction always is carried out on the first day of experiments to ensure that the catalyst is fully reduced. The procedure is a combination of the method for the reduction of copper chromite catalysts suggested by Engelhard and the procedure outlined by Tronconi, et.al. (11). Details can be found in last Semi-Annual Report (1).

\section{c. Data Collection}

\section{i. On-Line GC Analysis System}

The existing gas chromatograph is a dual-column, temperatureprogrammable instrument, equipped with both thermal conductivity (TCD) and flame ionization (FID) detectors. The chromatograph is interfaced with a computer that is used for both data acquisition and reduction. Fixed gases $(\mathrm{CO}$, 
$\mathrm{CO}_{2}, \mathrm{~N}_{2}, \mathrm{H}_{2}, \mathrm{H}_{2} \mathrm{O}$ ) are separated on a 15 foot long, $1 / 8$ in. o.d., 60/80 Carboxen1000 stainless steel column connected to a thermal conductivity detector (TCD). Higher $\left(\mathrm{C}_{2}^{+}\right)$alcohols, olefins, and paraffins are separated with a capillary column, Petrocol DH 150. The products eluting from this column are detected by a flame ionization detector (FID). Argon is the carrier gas for both columns. The temperature program is: initial temperature of $32{ }^{\circ} \mathrm{C}$ for 20 minutes; raise temperature to $180^{\circ} \mathrm{C}$ at a rate of $20^{\circ} \mathrm{C} / \mathrm{min}$; hold at $180^{\circ} \mathrm{C}$ for 20 minutes; reduce temperature to $150^{\circ} \mathrm{C}$ over a period of 2 minutes; hold for 20 minutes. The total analysis time is 77.4 minutes. Further details are available in References 2,7,8. Normally, at least 4 gas injections were performed each day.

\section{ii. Liquid Sample Collection}

Liquid samples were collected once per day from the liquid reflux line during the 8-day experiment. A sample of the liquid in the reactor after shutdown of this experiment ("spent" liquid) was obtained by filtering the catalyst slurry.

\section{iii. Catalyst Characterization}

The surface area of a used catalyst is an important parameter that may correlate with the activity of the catalyst. The BET surface areas of fresh and spent catalysts were measured with a Flow Sorb II 2300 instrument.

\section{d. Results and Discussion}

\section{i. Gas Product Analysis}

\section{- Data Reproducibility}

During the 8-day period of this experiment, data with the desired degree of reproducibility still was not achieved. In the last Semi-Annual Report (1), several possible explanations were advanced to account for the lack of data reproducibility. They were: variable $\mathrm{G} / \mathrm{L}$ separator temperature, intermittent slurry liquid makeup, on-line GC analysis system, and catalyst deactivation.

The newly-installed $\mathrm{G} / \mathrm{L}$ separator temperature controller is able to minimize variations in the $G / L$ separator temperature, and any variations in the outlet gas composition associated with these temperature variations. However, in the experiment described below, even with new $\mathrm{G} / \mathrm{L}$ temperature controller, reproducible data still was not achieved. We now theorize that intermittent liquid makeup (as opposed to continuous liquid makeup) is the major reason for the variable product composition. The liquid level change may have caused the mass-transfer characteristics of the slurry to become unfavorable towards the end of the period between liquid additions (high slurry viscosity, shortened distance between the gas sparger and the liquid level).

A continuous makeup of the slurry liquid will be used during the next experiment. 


\section{- G/L Separator Temperature Evaluation}

The effect of the $G / L$ separator temperature on the outlet gas composition was tested during the experiment. While keeping all other operating conditions constant, the $\mathrm{G} / \mathrm{L}$ separator temperature was raised from $155^{\circ} \mathrm{C}$ to $175^{\circ} \mathrm{C}$ and was then reduced to the original level. Even though the analytical data still were not consistent, there was no significant increase in the concentration of higher alcohols when the $G / L$ separator temperature was raised, and there was no significant change when the temperature was reduced again.

The rate of liquid loss from the reactor increases as the $G / L$ separator temperature is increased, requiring a higher rate of slurry liquid makeup. Therefore, a G/L separator temperature of $155^{\circ} \mathrm{C}$ will be used for subsequent runs.

\section{- Catalyst Productivity}

A preliminary comparison of the performance of the 6 wt.\% Cs catalyst with that of the $3 \mathrm{wt} . \%$ Cs catalyst and that of unpromoted zinc chromite catalyst was carried out. This comparison focused on the catalyst activity and selectivity. The catalyst activity was expressed in terms of catalyst productivity, where:

Species A Productivity (gr. A/kg.(cat.)-hr.) = Rate of Species A Production (gr. A/hr.)/ Weight of Catalyst (kg.)

The "Rate of Species A Production" was calculated from the flow rate and the analysis of the outlet gas.

The catalyst productivities for the main compounds in the product gas stream are shown in Fig. 2.1. This figure also shows a comparison between the productivities of the $6 \mathrm{wt} . \%, 3 \mathrm{wt} . \%$ and unpromoted catalysts. The productivities of the unpromoted zinc chromite catalyst were calculated from the data in Reference 3. The productivities of the $3 \mathrm{wt}$.\% Cs catalyst were reported in the last Semi-Annual Report (1). 


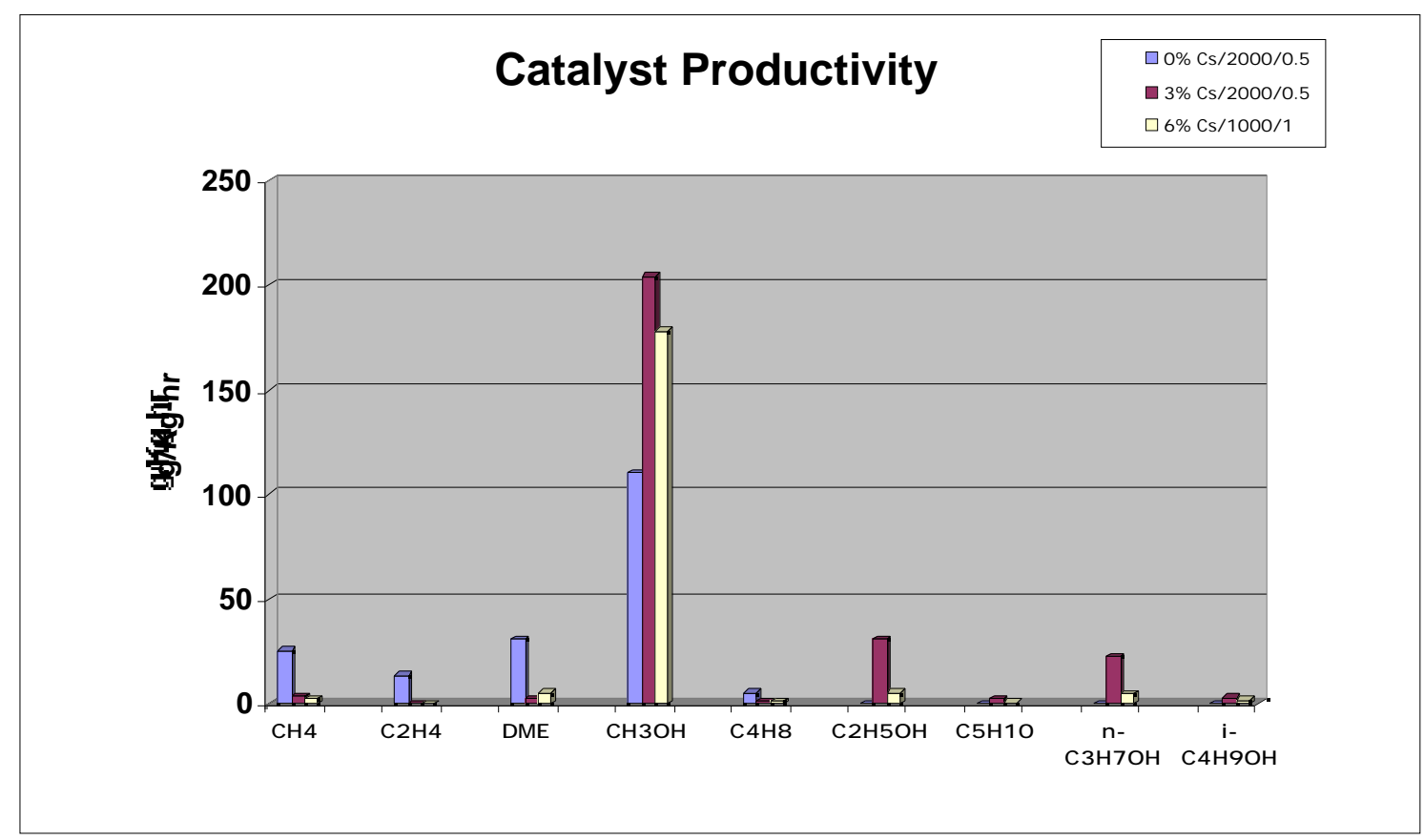

Fig. 2.1: Catalyst Productivities for Zinc Chromite Promoted with 6 wt.\% Cs and with 3 wt.\% Cs, and for Unpromoted Zinc Chromite Catalyst

$\left(\mathrm{T}=375^{\circ} \mathrm{C}, \mathrm{GHSV}=5000 \mathrm{sl} / \mathrm{kg}\right.$ (cat) hr, DHN; pressures in psig and the molar $\mathrm{H}_{2} / \mathrm{CO}$ feed ratio are shown in the key)

On a very preliminary basis, it appears that the Cs-promoted catalysts have a higher productivity for all of the alcohols, including methanol, and a lower productivity for most of the hydrocarbon species. The alcohol productivities for the zinc chromite catalyst promoted with 6 wt.\% Cs are lower than the alcohol productivities for the 3 wt.\% Cs catalyst. However, since the 6 wt.\% Cs catalyst was evaluated at a lower pressure (6.8 MPa versus 13.6 MPa) and a higher $\mathrm{H}_{2} / \mathrm{CO}$ feed ratio ( 1 versus 0.5 ), it is impossible to make an accurate comparison of these two catalysts.

\section{- Carbon Selectivity}

The carbon selectivity for a particular product is defined as the total number of carbons in that product divided by the total number of carbons in all of the products that are formed, i.e.:

Carbon Selectivity $($ Product $A)=$

Outlet Mole Fraction of Product A * Number of Carbons in Product A $\sum_{i}$ Outlet Mole Fraction of Product $i$ * Number of Carbons in Product

Preliminary selectivity data for the 6 wt.\% Cs catalyst, the 3 wt.\% Cs catalyst and the unpromoted catalyst are shown in the following figure. 


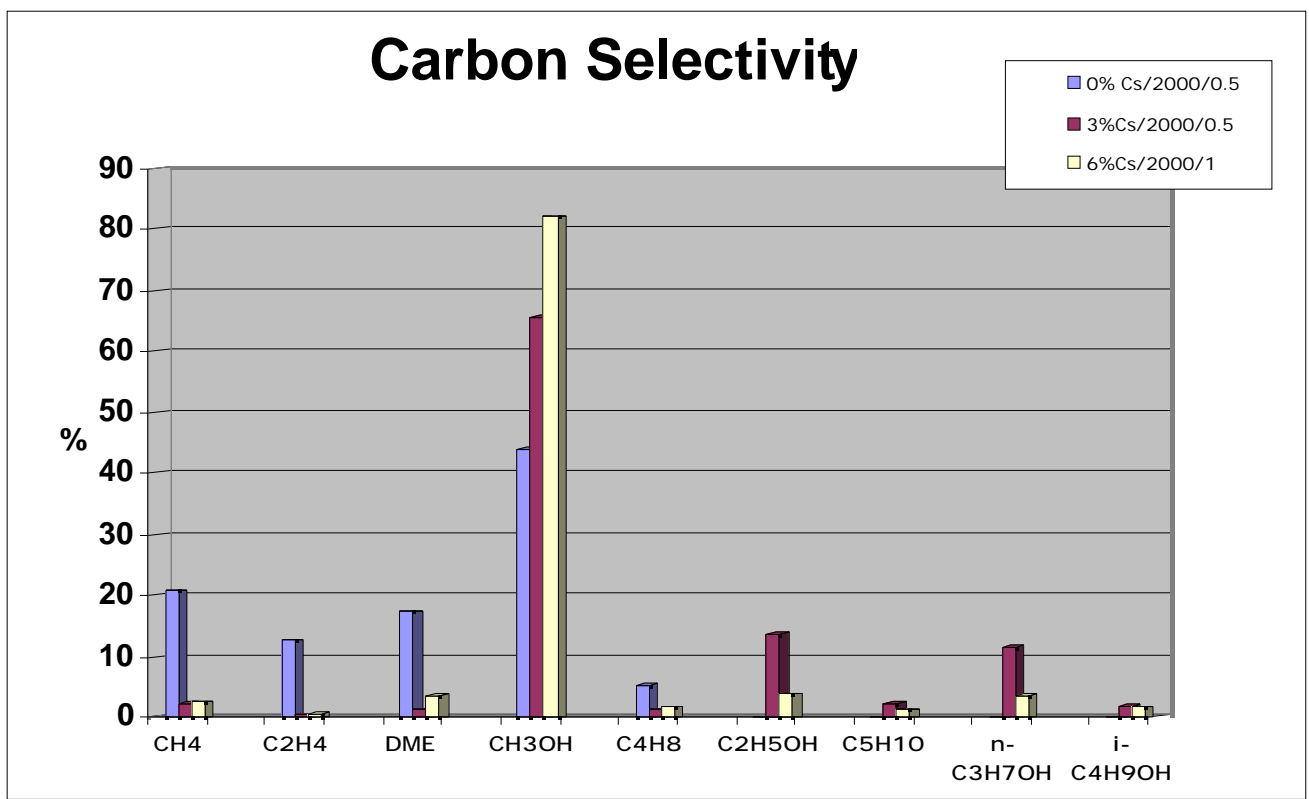

Fig. 2.2: Catalyst Selectivities for Zinc Chromite Promoted with 6 wt.\% Cs and with 3 wt.\% Cs, and for Unpromoted Zinc Chromite Catalyst

$\left(\mathrm{T}=375^{\circ} \mathrm{C}, \mathrm{GHSV}=5000 \mathrm{sl} / \mathrm{kg}\right.$ (cat) $\mathrm{hr}, \mathrm{DHN}$; pressures in psig and the molar $\mathrm{H}_{2} / \mathrm{CO}$ feed ratio are shown in the key)

Figure 2.2 shows that, on a very preliminary basis, the two Cs-promoted catalysts have a higher selectivity to all of the alcohols, including methanol, and a lower selectivity to most of the hydrocarbon species. Methanol is the predominant product, even with the promoted catalysts. Compared with the 3 wt.\% Cs catalyst, the 6 wt.\% catalyst appears more like a methanol catalyst. Again, since the $6 \mathrm{wt}$ \% catalyst was evaluated at a different operating pressure and $\mathrm{H}_{2} / \mathrm{CO}$ molar feed ratio, this comparison is preliminary and subject to change.

The following table shows a comparison of the total oxygenate and total hydrocarbon selectivities for the promoted and unpromoted catalysts.

Table 2.1: Total Oxygenates and Hydrocarbons Selectivities for Promoted and Unpromoted Zinc Chromite Catalysts

\begin{tabular}{l|c|c}
\hline Catalyst & $\begin{array}{c}\text { Total Oxygenates } \\
\text { Selectivity }(\%)\end{array}$ & $\begin{array}{c}\text { Total Hydrocarbons } \\
\text { Selectivity }(\%)\end{array}$ \\
\hline Unpromoted & 61 & 39 \\
\hline Promoted with 3 wt.\% Cs & 94 & 6 \\
\hline Promoted with 6 wt.\% Cs & 95 & 5 \\
\hline
\end{tabular}

The addition of Cs to the "parent" zinc chromite catalyst appears to shift the product distribution towards oxygenates and away from hydrocarbons. 


\section{ii. Liquid Analysis}

Analysis by GC/MS of the liquid samples obtained during this experiment showed that trans- and cis- DHN were the only compounds in the "spent" liquid and in the samples taken from the overhead system. This result corresponds to the results of the previous Thermal Stability Test with DHN $(1,6)$ and confirms that $\mathrm{DHN}$ is stable at reaction conditions. Based on this result, extension of the operating temperature of the slurry reactor to $400^{\circ} \mathrm{C}$ may be possible with DHN as the slurry liquid. This higher temperature should improve the kinetics of HAS.

\section{iii. Catalyst Characterization}

Table 2.2 shows the measured BET surface areas of the fresh and spent catalysts. There was a relatively large surface area loss for the $6 \mathrm{wt} . \% \mathrm{Cs}$ promoted catalyst after the 8-day run.

Table 2.2: Surface Area of Fresh and Spent Catalysts

\begin{tabular}{|c|c|c|c|c|}
\hline $\begin{array}{c}\text { Fresh } \\
\mathrm{Zn} / \mathrm{CrO} \\
\left(\mathrm{m}^{2} / \mathrm{g}\right)\end{array}$ & $\begin{array}{c}\text { Fresh } \\
6 \% \mathrm{Cs} / / \mathrm{Zn} / \mathrm{Cr} \\
\left(\mathrm{m}^{2} / \mathrm{g}\right)\end{array}$ & $\begin{array}{c}\text { Used } \\
6 \% \mathrm{Cs} / / \mathrm{Zn} / \mathrm{Cr} \\
\left(\mathrm{m}^{2} / \mathrm{g}\right) \\
\text { (8-day run) }\end{array}$ & $\begin{array}{c}\text { Fresh } \\
3 \% \mathrm{Cs} / / \mathrm{Zn} / \mathrm{Cr} \\
\left(\mathrm{m}^{2} / \mathrm{g}\right)\end{array}$ & $\begin{array}{c}\text { Used } \\
3 \% \mathrm{Cs} / / \mathrm{Zn} / \mathrm{Cr} \\
\left(\mathrm{m}^{2} / \mathrm{g}\right) \\
\text { (10-day run) }\end{array}$ \\
\hline 197 & 156 & 121 & 82 & 84 \\
\hline
\end{tabular}

As noted previously, the $6 \mathrm{wt} . \%$ Cs-promoted catalyst was prepared without a final, high-temperature calcination. However, the $3 \mathrm{wt}$ \% catalyst was calcined at $350^{\circ} \mathrm{C}$ to decompose the carbonate. This difference might be the reason that the initial surface area of the $6 \mathrm{wt}$.\% catalyst is so much greater than the initial surface area of the $3 \mathrm{wt} . \%$ catalyst, and may account for the larger surface area loss experienced by the $6 \mathrm{wt}$. $\%$ catalyst.

\section{e. Future Research}

After the new Maxpro gas booster (DLE 15-75) arrives, experiments with the same 6 wt.\% Cs-promoted $\mathrm{Zn} / \mathrm{Cr}$ catalysts will be carried out at $13.6 \mathrm{MPa}$ (2000 psig). Different operating conditions will be tested, such as a $\mathrm{H}_{2} / \mathrm{CO}$ ratio between 0.5 and 2 , and an operating temperature from 375 to $400^{\circ} \mathrm{C}$. The liquid makeup will be added continuously.

\section{Analysis of Slurry Liquid}

To understand the influence of different slurry liquids on the HAS reaction, it is important to define any reaction in which a slurry liquid molecule might participate, i.e., to define the final composition of the slurry liquid after a catalystevaluation experiment is concluded. This is done by analyzing the "spent" slurry liquid to identify the compounds that are present. 
During this report period, most of the effort in this area was spent on analyzing crude fractions that were obtained by means of silica gel liquid chromatography (LC). The details of the experimental setup and the procedure that was used to obtain the crude fractions were described in last Semi-Annual Report (1). These fractions were analyzed by means of gas chromatography/mass spectrometry (GC/MS). Each fraction collected via LC, a total of approximately 120 samples, was analyzed by thin-layer chromatography (TLC). Fractions which contained essentially the same compounds, as determined by TLC, were combined. Approximately 20 of these combined fractions were analyzed by GC/MS.

The silica gel LC column was unable to resolve the "spent" THQ into pure compounds. Each of the approximately 120 fractions typically contained between 2 and 4 individual compounds. Therefore, NMR analysis could not provide any useful information. However, GC/MS analysis was able to define general chemical formuli and the probable structure for each major compound in the crude fractions. Table 3.1 shows all of the major compounds in the "spent" $\mathrm{THQ}$, based on GC/MS analysis.

The structures shown below are the most probable structures according to the GC/MS internal library. Further information is needed to determine the exact structure of each compound. It is very important to know whether the alkyl group is attached on a carbon atom or on the nitrogen atom, whether it is located on a saturated or an unsaturated ring, and whether a compound with, say, 2 alkyl carbons is a dimethyl or an ethyl compound.

Nuclear magnetic resonance (NMR) analysis is the best way to answer these questions. However, a fraction containing a single pure compound is required for NMR analysis. Therefore, high-performance liquid chromatography (HPLC) will be used to achieve further separation of the crude fractions obtained by LC.

Ms. Xiaolei Sun, the graduate student assigned to this project, completed NMR training in February, through the services of the NMR Laboratory, Chemistry Department, North Carolina State University. 
Table 3.1: GC/MS Analysis Results

Formula

\section{Conclusions}

1. On a very preliminary basis, it appears that a zinc chromite catalyst promoted with $6 \mathrm{wt} . \% \mathrm{Cs}$ has approximately the same total alcohol productivity as a 3 wt.\% Cs catalyst. Like the 3 wt.\% catalyst, the 6 wt.\% catalyst has a higher total alcohol productivity and selectivity than the unpromoted $\mathrm{Zn} / \mathrm{Cr}$ catalyst. The 6 wt.\% catalyst appears to have a higher methanol selectivity than the 3 wt.\% catalyst.

2. Experimental data showed that there is no significant higher alcohols condensation in the $\mathrm{G} / \mathrm{L}$ separator at $155^{\circ} \mathrm{C}$. 
3. Crude fractions of "spent" THQ were analyzed by GC/MS. General formuli and probable structures for each major component were obtained. However, a higher degree of purification is necessary to allow NMR analysis to be used for a definitive compound identification.

\section{References}

1. Sun, X., Roberts, G. W., Promoted Zinc Chromite Catalysts for Higher Alcohol Synthesis: Semi-Annual Report (Period Ending 9/30/99).

2. Sun, X., Roberts, G. W., Promoted Zinc Chromite Catalysts for Higher Alcohol Synthesis: Semi-Annual Report (Period Ending 3/31/99).

3. Márquez, M. A., The stability of liquids and the effect of their composition on the production of methanol in a slurry reactor, M.S. Thesis, North Carolina State University, NC, April (1996).

4. McCutchen, M. S., Synthesis of alcohols from carbon monoxide and hydrogen in a slurry reactor, Ph.D Thesis, North Carolina State University, NC, (1996)

5. Roberts, G. W., Marco A. Márquez, M. A., McCutchen, M. S., Haney, C. A. and Shin, I. D., High-Temperature Slurry Reactors for Synthesis Gas Reactions. I. Liquid Thermal Stability, Ind. Eng. Chem. Res., 36, 4143-4154 (1997).

6. Roberts, G. W., Marquez, M. A., and Haney, C. A. Liquid/catalyst interactions in slurry reactors: methanol synthesis over zinc chromite, Applied Catalysis A: General, 183, 395-410 (1999).

7. Sun, X., Roberts, G. W., Promoted Zinc Chromite Catalysts for Higher Alcohol Synthesis: Semi-Annual Report (Period Ending 3/31/98).

8. Sun, X., Roberts, G. W., Promoted Zinc Chromite Catalysts for Higher Alcohol Synthesis: Semi-Annual Report (Period Ending 9/30/98).

9. Forzatti, P., Tronconi, E. and Pasquon, I. Higher alcohol synthesis, Cat. Rev.Sci.Eng. 33(1\&2), 109-168 (1991).

10. Beretta, A., Tronconi, E., Forzatti, P. and Pasquon, I. Development of a mechanistic kinetic model of the higher alcohol synthesis over Cs-doped $\mathrm{Zn} / \mathrm{Cr} / \mathrm{O}$ catalysts. 1. Model derivation and data fitting, Ind. Eng. Chem. Res. $35,2144-2153$ (1996) 
11. Tronconi E, Ferlazzo N, Forzatti P and Pasquon I, Synthesis of alcohols from carbon oxides and hydrogen. 4. Lumped kinetics for the higher alcohol synthesis over a Zn-Cr-K oxide catalyst, Ind. Eng. Chem. Res. 26, 2122-2129 (1987). 